\title{
3 Research Soure

\section{Effectiveness comparison of Zero-profile interbody fusion implant and anterior cervical plate interbody fusion device: a clinical and radiological study}

Jun Zhang

Wuhan Tongji Hospital

Xiangyu Tang

Wuhan Tongji Hospital

Wei Xiong

Wuhan Tongji Hospital

Hua Wu

Wuhan Tongji Hospital

Chaoxu Liu(Former Corresponding Author)

Wuhan Tongji Hospital

Feng Li(New Corresponding Author) ( $\sim$ lifengtongjiguke@163.com )

Wuhan Tongji Hospital

Research article

Keywords: Cage, Zero-profile implant, Anterior cervical discectomy and fusion, Subsidence, Dysphagia

Posted Date: March 20th, 2020

DOl: https://doi.org/10.21203/rs.3.rs-16292/v2

License: () (1) This work is licensed under a Creative Commons Attribution 4.0 International License.

Read Full License 


\section{Abstract}

Background Anterior cervical discectomy and fusion (ACDF) is a successful strategy to relieve the symptoms caused by cervical degenerative disease. Postoperative dysphagia is one complication of this kind of surgery. We performed this study to compare the clinical outcomes, radiographic parameters, and complications of ACDF with a Zero-profile implant (Zero-P) and titanium plate and cage.

Methods There were 68 patients received ACDF of single level, 35 patients with Zero-profile implant (Zerop group) and 33 patients with traditional plate and cage (Cage group), from C3-C7 during 2014 to 2016. Collecting and analyzing of clinical and radiological data were performed. Patients were followed-up at least 1 year after surgery. The operation time, blood loss, Japan Department of Orthopedics Association (JOA) score, pain Visual Analogue Score (VAS), Neck Disability Index (NDI) score and dysphagia score were recorded. Additionally, changes in cervical lordosis, fusion rate and adjacent segment degeneration were analyzed as well.

Results For neurologic outcomes, the JOA, VAS and NDI were statistically equivalent between the two groups $(P>0.05)$. For radiographic outcomes, there were no significant differences in the $\mathrm{C} 2-7 \mathrm{Cobb}$ angles, segmental Cobb angle and incidence of subsidence at the final follow-up $(P>0.05)$. No degenerative changes was found in the Zero-p group, whereas 5 patients in the Cage group developed degeneration in adjacent segments $(P<0.05)$. Also, the incidence of postoperative dysphagia is higher in Cage group than in Zero-p group at 3 months and 12 months $(P<0.05)$.

Conclusions Both Zero-profile implant and anterior cervical plate interbody fusion device were demonstrated to be effective and safe strategies in this study. Considering the lower incidences of dysphagia and degenerative changes, the Zero-profile implant is a good succedaneum.

\section{Introduction}

The cervical spondylosis is a common spine degenerative disease resulted from the stimulation or compression of adjacent spinal cord caused by degenerative changes of cervical spine structure. Symptoms include neck and arm pain associated with radiculopathy or myelopathy $[16,23,31]$. According to a correlating clinical symptoms and the evidence of root or spinal cord compression from recent radiological examination, the surgical intervention is indicated as below: 1 . clinical symptoms are severe and progressive, which effect patients' normal life a lot; 2 . conservative treatment is not effective [28]. As a golden standard, anterior cervical discectomy and fusion (ACDF) has been widely introduced in patients with cervical spondylosis disease since the 1950s. Some studies have suggested that the ACDF with cervical plates and intervertebral cages brings more satisfying fusion rates and a lower occurrence of failure [26], but a higher incidence of plate-associated complications such as postoperative dysphagia $[3,12,24]$.

To prevent the issues, zero profile anchored spacer (Zero-P) has been advocated by some researchers (Synthes, Zuchwil, Switzerland). The advantage of Zero-P is likely to supply immediate stability. 
Moreover, it has been widely reported to be a promising strategy in reducing the occurrence of postoperative dysphagia $[2,25,30]$. The purpose of our study is to compare the clinical outcomes and radiologic results of patients receiving the Zero-P spacer with those using titanium plate and cage implants.

\section{Materials And Methods}

\section{Patients:}

A total of 68 patients were enrolled in this study from 2016 to 2018 . The criterion for enrolling is that: 1 . Patients have the symptoms of the cervical spondylosis. 2. Symptoms have had a deep influence on the normal life. 3. Symptoms are severe and progressive.4. It's ineffective for at least 3 months conservative treatment. 5 . The indication for surgery was according to the clinical symptoms correlated with recent radiological evidence of root or spinal cord compression.

Single level ACDF were performed for all patients. 33 operations were performed with a traditional plate and cage (Cage group), and the others were treated with Zero-P (Zero-P group). The indication of performing ACDF for these patients was the same and the device used in the operation was selected randomly.

\section{Clinical outcomes}

The data about surgical procedure (operation time, intraoperative blood loss) were recorded. All of the patients completed the questionnaires of JOA, VAS and NDI before the operation, 3months and 12 months postoperatively. Additionally, complications were recorded, such as dysphagia, the looseness and pulling away of screws, and adjacent segment degeneration. The presence of dysphagia was assessed using the system designed by Bazaz [3] at 1 week, 3 months and 12 months postoperatively (Table 1).

\section{Radiographic evaluations}

The $\mathrm{CT}$ and MRI examinations were performed before the operation for all patients. Anteroposterior and lateral X-rays with the neck in neutral position, flexion and extension X-rays were taken before the operation and 1 week, 3 months and 12 months postoperatively.

Cervical alignment (Cobb C) was calculated by the Cobb angle between the lines perpendicular to the upper planes of the $\mathrm{C} 2$ vertebral body and the lower plane of the $\mathrm{C} 7$ vertebral body. The segmental angle (Cobb S) was evaluated with the angle between the lines perpendicular to the superior margin of the cranialis vertebral body and the inferior margin of the caudal vertebral body involved in the operation level (Fig.1). The Cobb $\mathrm{C}$ and Cobb $\mathrm{S}$ were obtained at preoperative, 3 months postoperative and final follow-up to evaluate the aggravation of kyphosis [5] .

The criteria of bone fusion was defined as: 1. less than 10-degree movement on lateral flexion/extension views; 2 . presence of trabecular bridging across the bone-graft interface; 3 . less than $50 \%$ radiolucency in 
the perimeter surrounding the cage; and 4. no evidence of pullout of the device [5].

The total interbody height $(\mathrm{TIH})$ of segmental level was measured preoperatively, 3 months postoperative, and at the final follow-up assessment to assess the subsidence of implants [14]. TIH was identified as the length from the midpoint of the upper end plate of the cranial vertebral body to the lower end plate of the caudal vertebral body on lateral X-ray views (Fig. 1). The occurrence of subsidence was defined as $\mathrm{TIH}$ in final assessment decreased $>2 \mathrm{~mm}$ from that 1 week postoperative on lateral $\mathrm{X}$-ray views. Additionally, we also recorded the number of patients with bony spurs' formation, which is the indication of degenerative changes of the adjacent segment (Fig. 2).

\section{Statistical analysis}

The data was analyzed with SPSS for Windows Version 24.0 and expressed as means \pm standard deviation. The quantitative data was analyzed by U-test. The qualitative data was analyzed by the Chisquare test. The $P$ value $<0.05$ was considered statistically significant.

\section{Results}

\section{Surgical Details}

Through the comparison, the difference of the age, gender, surgical level between the two groups were not significantly different $(P>0.05)$. The operative time and blood loss in the two groups were as showed in the Table 1. Though the mean operative time and mean blood loss in the Zero-p group was less slightly, obvious difference was observed only for operative time $(P<0.05)$ (Table 2).

\section{Clinical Outcome and Complications}

The postoperative JOA, VAS and NDI at 3months, 12months postoperative were higher than their respective preoperative data in both groups, and the difference was different obviously $(P<0.05)$. Between the two groups, significant difference was not found for JOA, NDI and VAS at the every follow-up respectively $(P>0.05)$ but the JOA score at 12 months postoperative $(P<0.05)$ (Table 3$)$.

At 1 week postoperatively, five patients in Zero-p group complained mild dysphagia and seven patients in Cage group complained mild $(n=6)$ or moderate $(n=1)$ dysphagia $(P>0.05)$. At the 3 month postoperatively, only one patient in Zero-p group still had mild dysphagia, which had been resolved completely by 12 months. In Cage group, six and four patients still had mild dysphagia at 3 and 12 months postoperatively respectively (Table 3 ). The occurrence of dysphagia was different significantly between the two groups 3 months and 12 months postoperatively $(p<0.05)$.

\section{Radiographic Outcome}

Compared with the preoperative value, the value of Cobb $\mathrm{C}$ and Cobb $\mathrm{S}$ was improved for both groups at the 3 months and 12 months postoperatively $(P<0.05)$. In Cage group, the Cobb $C$ was $13.91 \pm 4.43$ at the 
3-month postoperative, which was decreased to $11.40 \pm 3.19$ at the final follow-up. Meanwhile, Cobb C was $14.25 \pm 3.56$ and $12.30 \pm 2.86$ in the Zero-P group at the 3-month and final follow-up, respectively. Similarly, the Cobb S for the Cage group decreased from 7.08 \pm 2.363 months after the operation to postoperative assessment to $6.68 \pm 2.65$ at the final follow-up. In the Zero P group, Cobb S increased from $6.11 \pm 2.27$ at the 3-month postoperative assessment to $7.19 \pm 1.74$ at the final follow-up assessment. No significant difference was observed between two groups for both Cobb $\mathrm{C}$ and $\mathrm{Cobb} \mathrm{S}$ at any time after surgery (Table 4).

Regarding the extent of $\mathrm{TIH}$, the two groups had a significant increase of the distance between the vertebral bodies at 3 months after surgery $(P<0.05)$. Through the observation of $\mathrm{TIH}$, subsidence occurred in five patients of the Cage group and four patients of the Zero-p group at final follow-up. The occurrence rate about subsidence was not significantly different between the groups $(P>0.05)$ (Table 5).

In the follow-up, we didn't observe looseness and pulling away of screws. Bone fusion was found in $97 \%$ and $100 \%$ of the Cage group and the Zero-P group, respectively. No significant difference was detected about the fusion rate between two groups $(P>0.05)$ (Table 5).

The number of patients with bony spurs was four in Cage group and none in the Zero-p group, respectively (Fig. 2). The incidence of bony spurs was different significantly between the two groups $(P<0.05)$. Moreover, there was one patient formed a new cervical disc herniation with the evidence of MRI.

\section{Discussion}

ACDF is the standard surgical treatment for cervical spondylosis when conservative treatment failed [18]. With increasing experience, number of reports had authenticated the effectiveness of additional plate to treat degenerative spine disorders $[9,26,27]$. It was demonstrated that plate benefited the higher fusion rate and immediate postoperative stability, and decreased the occurrence of pseudarthrosis $[1,4]$. It also prevented interbody cage dislocation and subsidence, which might occur after multilevel procedures [22]. Despite this treatment was widely accepted, it also had a number of drawbacks, one of which was dysphagia postoperatively $[7,11,21]$.

Chronic dysphagia is a common complication of ACDF. It was reported that the incidence of this complication varied from $3 \%$ up to $21 \%[3,13,17,25]$. There are several potential reasons for dysphagia, such as soft tissue swelling, hematoma, esophageal injury, and adhesion formation around implanted cervical plates [8] . Additionally, adjacent segment degeneration is other complication companying with the implant of plate [15]. To solve these problems, stand-alone cage was supposed to be a good alteration and it was proved to bring satisfying outcomes [21,29]. However, a relatively high occurrence of implant subsidence could be caused by stand-alone cages followed with secondary kyphotic deformity. This might be a potential reason of adjacent cervical segment disease further [10]. Therefore, cage screw devices that can provide immediate biomechanical stability, as anterior cervical plates, have been developed (e.g., Zero-P by DePuy Synthes). 
As we know, extension instability is the basic disadvantage of stand-alone cages. To eliminate this, the integral part of the Zero-P spacer is a plate and screw system [14, 19, 21]. It was reported that either the Zero-P spacer or traditional titanium plate with cage has satisfying effect to improve the symptoms of cervical degeneration disease. However, less dysphagia was observed in the Zero-P group [30]. Additionally, it was inferred that utilization of the Zero-P spacer could decrease adjacent level spondylosis, potential mechanism of which was the less stress to adjacent level conveyed by Zero-P device. Similar conclusion was obtained in other studies $[25,30]$. In this study, we also find the incidence of dysphagia was lower in Zero-p group at 3 months and 12 months after surgery, compared to the cage group $(P<0.05)$. From all, we concluded that the zero-p can take a lower occurrence of dysphasia.

Referring the clinical effectiveness appraised by JOA, VAS and NDI, both groups had a significant improvement in the respect of neurological function and symptom. The symptoms of cervical spondylosis are due to the stimulation or compression of the degenerative intervertebral disc. The degenerative disc was removed thoroughly in both two groups. Thus, either the Zero-p or traditional plate and cage can contribute good clinical outcomes.

Adjacent segment degeneration (ASD) was confirmed when the reduction of height, instability, or osteophyte formation happened in the adjacent intervertebral space. The fusion of surgical segment caused a increasement of stress on adjacent segment $[6,20]$. Additionally, application of anterior plate irritated the adjacent segment, which will lead to formation of bony spurs and degenerative changes [32]. Through the observation of lateral X-ray, there were none patient in zero-p group while 4 patients in cage group had bony spurs at final follow-up in this study. The difference is significant $(P<0.05)$. Moreover, one patient formed new cervical disc herniation in cage group after 12 months.

\section{Conclusions}

The results of this study showed a good result for both zero-p implant and traditional titanium plate with cage for cervical degenerative disc disease in terms of improvement in clinical outcomes (JOA scores, VAS scores, NDI scores, fusion rate) and correction of Cobb C and Cobb S. We concluded that either zero$\mathrm{p}$ implant or the traditional titanium plate with cage was an effective treatment for single level cervical spondylosis. However, the incidence of adjacent segments degeneration and dysphagia are lower in zerop group. In addition, the zero-p implant is associated with shorter operation time and relatively greater simplicity than the traditional titanium plate with cage. Therefore, the zero-p implant is a good succedaneum for traditional titanium plate with cage. However, a prospective trial with more patients and longer follow-ups are required to confirm these observations.

\section{Declarations}

\section{Acknowledgments}

The authors thank Dr.Tian Ma and Dr.Yingchi Zhang for statistical consultation. 


\section{Funding}

This work was finically supported by National Natural Sciences Foundation of China (51877097, 51907077, 51537004).

\section{Availability of data and materials}

The authors can not share the raw data and materials.

\section{Authors' contributions}

$\mathrm{JZ}$, a resident, contributed to data analysis. $\mathrm{XT}$, a senior radiologist, contributed to data collection. WX, a senior surgeon, contributed to data analysis. HW and CL, senior surgeons, drafted the manuscript. FL, a senior surgeon, performed surgeries and drafted the manuscript. The final manuscript was read and approved by all the authors.

\section{Ethics approval and consent to participate}

This study was approved by the ethics committee of Tongji Hospital, HUST, Wuhan, China. The committee waived the informed consent from the patients.

\section{Consent for publication}

Not applicable. No individual data of patients were included in this article.

\section{Competing interests}

The authors declare that they have no competing interest

\section{References}

1. Anderson DG, Albert TJ. Bone grafting, implants, and plating options for anterior cervical fusions. The Orthopedic clinics of North America. 2002;33:317-328.

2. Azab W, Abdel-Razek M, Ali A, Abdelrahman A, Salaheldin W, Nasim K, Attia H, Soliman D. Outcome evaluation of a zero-profile implant for anterior cervical diskectomy with fusion. Turkish neurosurgery. 2012;22:611-617.

3. Bazaz R, Lee MJ, Yoo JU. Incidence of dysphagia after anterior cervical spine surgery: a prospective study. Spine. 2002;27:2453-2458.

4. Bohler J, Gaudernak T. Anterior plate stabilization for fracture-dislocations of the lower cervical spine. The Journal of trauma. 1980;20:203-205.

5. Cho HJ, Hur JW, Lee JB, Han JS, Cho TH, Park JY. Cervical Stand-Alone Polyetheretherketone Cage versus Zero-Profile Anchored Spacer in Single-Level Anterior Cervical Discectomy and Fusion : 
Minimum 2-Year Assessment of Radiographic and Clinical Outcome. Journal of Korean Neurosurgical Society. 2015;58:119-124.

6. Eck JC, Humphreys SC, Lim TH, Jeong ST, Kim JG, Hodges SD, An HS. Biomechanical study on the effect of cervical spine fusion on adjacent-level intradiscal pressure and segmental motion. Spine. 2002;27:2431-2434.

7. Fernandez-Fairen M, Sala P, Dufoo M, Jr., Ballester J, Murcia A, Merzthal L. Anterior cervical fusion with tantalum implant: a prospective randomized controlled study. Spine. 2008;33:465-472.

8. Fountas KN, Kapsalaki EZ, Nikolakakos LG, Smisson HF, Johnston KW, Grigorian AA, Lee GP, Robinson JS, Jr. Anterior cervical discectomy and fusion associated complications. Spine. 2007;32:2310-2317.

9. Fraser JF, Hartl R. Anterior approaches to fusion of the cervical spine: a metaanalysis of fusion rates. Journal of neurosurgery. Spine. 2007;6:298-303.

10. Gercek E, Arlet V, Delisle J, Marchesi D. Subsidence of stand-alone cervical cages in anterior interbody fusion: warning. European spine journal : official publication of the European Spine Society, the European Spinal Deformity Society, and the European Section of the Cervical Spine Research Society. 2003;12:513-516.

11. Hacker RJ, Cauthen JC, Gilbert TJ, Griffith SL. A prospective randomized multicenter clinical evaluation of an anterior cervical fusion cage. Spine. 2000;25:2646-2654; discussion 2655.

12. Hwang SL, Lin CL, Lieu AS, Lee KS, Kuo TH, Hwang YF, Su YF, Howng SL. Three-level and four-level anterior cervical discectomies and titanium cage-augmented fusion with and without plate fixation. Journal of neurosurgery. Spine. 2004;1:160-167.

13. Kalb S, Reis MT, Cowperthwaite MC, Fox DJ, Lefevre R, Theodore N, Papadopoulos SM, Sonntag VK. Dysphagia after anterior cervical spine surgery: incidence and risk factors. World neurosurgery. 2012;77:183-187.

14. Kandziora F, Pflugmacher R, Schafer J, Born C, Duda G, Haas NP, Mittlmeier T. Biomechanical comparison of cervical spine interbody fusion cages. Spine. 2001;26:1850-1857.

15. Kao FC, Niu CC, Chen LH, Lai PL, Chen WJ. Maintenance of interbody space in one- and two-level anterior cervical interbody fusion: comparison of the effectiveness of autograft, allograft, and cage. Clinical orthopaedics and related research. 2005:108-116.

16. Karadimas SK, Erwin WM, Ely CG, Dettori JR, Fehlings MG. Pathophysiology and natural history of cervical spondylotic myelopathy. Spine. 2013;38:S21-36.

17. Lee MJ, Bazaz R, Furey CG, Yoo J. Influence of anterior cervical plate design on Dysphagia: a 2-year prospective longitudinal follow-up study. Journal of spinal disorders \& techniques. 2005;18:406-409.

18. Li J, Zheng Q, Guo X, Zeng X, Zou Z, Liu Y, Hao S. Anterior surgical options for the treatment of cervical spondylotic myelopathy in a long-term follow-up study. Archives of orthopaedic and trauma surgery. 2013;133:745-751.

19. Matge G. Cervical cage fusion with 5 different implants: 250 cases. Acta neurochirurgica. 2002;144:539-549; discussion 550. 
20. Park DH, Ramakrishnan P, Cho TH, Lorenz E, Eck JC, Humphreys SC, Lim TH. Effect of lower two-level anterior cervical fusion on the superior adjacent level. Journal of neurosurgery. Spine. 2007;7:336340.

21. Peolsson A, Vavruch L, Hedlund R. Long-term randomised comparison between a carbon fibre cage and the Cloward procedure in the cervical spine. European spine journal : official publication of the European Spine Society, the European Spinal Deformity Society, and the European Section of the Cervical Spine Research Society. 2007;16:173-178.

22. Pitzen TR, Chrobok J, Stulik J, Ruffing S, Drumm J, Sova L, Kucera R, Vyskocil T, Steudel WI. Implant complications, fusion, loss of lordosis, and outcome after anterior cervical plating with dynamic or rigid plates: two-year results of a multi-centric, randomized, controlled study. Spine. 2009;34:641-646.

23. Rafael H. Cervical spondylotic myelopathy: surgical results and factors affecting outcome with special reference to age differences. Neurosurgery. 2003;53:787; author reply 787-788.

24. Riley LH, 3rd, Skolasky RL, Albert TJ, Vaccaro AR, Heller JG. Dysphagia after anterior cervical decompression and fusion: prevalence and risk factors from a longitudinal cohort study. Spine. 2005;30:2564-2569.

25. Scholz M, Schnake KJ, Pingel A, Hoffmann R, Kandziora F. A new zero-profile implant for stand-alone anterior cervical interbody fusion. Clinical orthopaedics and related research. 2011;469:666-673.

26. Song KJ, Taghavi CE, Lee KB, Song JH, Eun JP. The efficacy of plate construct augmentation versus cage alone in anterior cervical fusion. Spine. 2009;34:2886-2892.

27. Troyanovich SJ, Stroink AR, Kattner KA, Dornan WA, Gubina I. Does anterior plating maintain cervical lordosis versus conventional fusion techniques? A retrospective analysis of patients receiving singlelevel fusions. Journal of spinal disorders \& techniques. 2002;15:69-74.

28. Vanek P, Bradac O, Delacy P, Lacman J, Benes V. Anterior interbody fusion of the cervical spine with Zero-P spacer: prospective comparative study-clinical and radiological results at a minimum 2 years after surgery. Spine. 2013;38:E792-797.

29. Vavruch L, Hedlund R, Javid D, Leszniewski W, Shalabi A. A prospective randomized comparison between the cloward procedure and a carbon fiber cage in the cervical spine: a clinical and radiologic study. Spine. 2002;27:1694-1701.

30. Wang ZD, Zhu RF, Yang HL, Gan MF, Zhang SK, Shen MJ, Chen C, Yuan Q. The application of a zeroprofile implant in anterior cervical discectomy and fusion. Journal of clinical neuroscience : official journal of the Neurosurgical Society of Australasia. 2014;21:462-466.

31. Yamazaki T, Yanaka K, Sato H, Uemura K, Tsukada A, Nose T. Cervical spondylotic myelopathy: surgical results and factors affecting outcome with special reference to age differences. Neurosurgery. 2003;52:122-126; discussion 126.

32. Yue WM, Brodner W, Highland TR. Persistent swallowing and voice problems after anterior cervical discectomy and fusion with allograft and plating: a 5- to 11-year follow-up study. European spine journal : official publication of the European Spine Society, the European Spinal Deformity Society, and the European Section of the Cervical Spine Research Society. 2005;14:677-682. 


\section{Tables}

\begin{tabular}{|lll|}
\hline Symptom severity & Liquid food & Solid food \\
\hline None & None & None \\
\hline Mild & None & Rare \\
\hline Moderate & None or rare & Occasionally (only with specific food) \\
\hline Severe & None or rare & Frequent (majority of solids) \\
\hline
\end{tabular}

Table 1

Bazaz grading system for dysphagia

\begin{tabular}{|llll|}
\hline & Cage & Zero-p & P value \\
\hline Patients number & 33 & 35 & \\
\hline Sex(male/female) & $17 / 16$ & $20 / 15$ & 0.641 \\
\hline Age & $47.8 \pm 11.0$ & $49.6 \pm 9.1$ & 0.583 \\
\hline Surgical sites & & & 0.809 \\
\hline C3-4 & 4 & 2 & \\
\hline C4-5 & 3 & 5 & \\
\hline C5-6 & 24 & 26 & \\
\hline C6-7 & 2 & 2 & 0.006 \\
\hline Operation time(min) & $162.0 \pm 34.1$ & $141.9 \pm 23.9$ & 0.280 \\
\hline Blood loss & $30.8 \pm 72.2$ & $67.9 \pm 95.6$ & \\
\hline Cage, the conventional cage-plate group; Zero-p, the Zero-p group. \\
\hline
\end{tabular}

Table 2

Demographic and Surgical Data 


\begin{tabular}{|llll|}
\hline & Cage & Zero-p & P value \\
\hline JOA & & & \\
\hline Preoperative & $12.46 \pm 1.61$ & $12.07 \pm 2.34$ & 0.830 \\
\hline Postoperative 3 months & $14.62 \pm 0.87$ & $14.79 \pm 1.48$ & 0.375 \\
\hline Postoperative 12 months & $15.61 \pm 0.97$ & $15.97 \pm 0.86$ & 0.103 \\
\hline NDI & & & \\
\hline Preoperative & $14.69 \pm 7.543$ & $16.00 \pm 9.013$ & 1.000 \\
\hline Postoperative 3 months & $6.69 \pm 4.922$ & $4.00 \pm 7.863$ & 0.943 \\
\hline Postoperative 12 months & $6.23 \pm 5.862$ & $4.43 \pm 5.185$ & 0.302 \\
\hline VAS & & & \\
\hline Preoperative & $5.31 \pm 3.146$ & $5.43 \pm 3.251$ & 0.981 \\
\hline Postoperative 3 months & $2.23 \pm 2.127$ & $1.79 \pm 2.293$ & 0.650 \\
\hline Postoperative 12 months & $1.38 \pm 2.103$ & $0.64 \pm 1.216$ & 0.402 \\
\hline Dysphagia & & & \\
\hline Postoperative 1 week & $7 / 33(21.2 \%)$ & $5 / 35(14.3 \%)$ & 0.453 \\
\hline Postoperative 3 months & $6 / 33(18.2 \%)$ & $1 / 35(2.3 \%)$ & 0.038 \\
\hline Postoperative 12 months & $4 / 33(12.1 \%)$ & $0 / 35(0 \%)$ & 0.034 \\
\hline
\end{tabular}

Table 3

Clinical outcomes 


\begin{tabular}{|llll|}
\hline & Cage & Zero-p & P value \\
\hline Cobb C $\left(^{\circ}\right)$ & & & \\
\hline Preoperative & $8.52 \pm 3.16$ & $9.15 \pm 2.23$ & 0.241 \\
\hline Postoperative 3 months & $13.91 \pm 4.43$ & $14.25 \pm 3.56$ & 0.443 \\
\hline Postoperative 12 months & $11.40 \pm 3.19$ & $12.30 \pm 2.86$ & 0.229 \\
\hline Cobb S $\left(^{\circ}\right)$ & & & \\
\hline Preoperative & $3.98 \pm 1.49$ & $3.50 \pm 1.48$ & 0.191 \\
\hline Postoperative 3 months & $6.68 \pm 2.65$ & $6.11 \pm 2.27$ & 0.418 \\
\hline Postoperative 12 months & $7.08 \pm 2.36$ & $7.19 \pm 1.74$ & 0.902 \\
\hline TIH (cm) & & & \\
\hline Preoperative & $3.18 \pm 0.22$ & $3.11 \pm 0.19$ & 0.466 \\
\hline Postoperative 3 months & $3.45 \pm 0.36$ & $3.47 \pm 0.26$ & 0.180 \\
\hline Postoperative 12 months & $3.31 \pm 0.22$ & $3.30 \pm 0.19$ & 0.141 \\
\hline
\end{tabular}

Table 4

Radiographic outcomes

\begin{tabular}{|llll|}
\hline & Cage & Zero-p & P value \\
\hline Subsidence & $5(15.2 \%)$ & $4(11.4 \%)$ & 0.651 \\
\hline Fusion (yes/no)(\%) & $32 / 1(97.0 \%)$ & $35 / 0(100 \%)$ & 0.299 \\
\hline Bony spurs (yes/no) (\%) & $4 / 29(12.1 \%)$ & $0 / 35(0 \%)$ & 0.034 \\
\hline
\end{tabular}

Table 5

Radiological outcomes of Fusion rate, Subsidence and Bony spurs

\section{Figures}




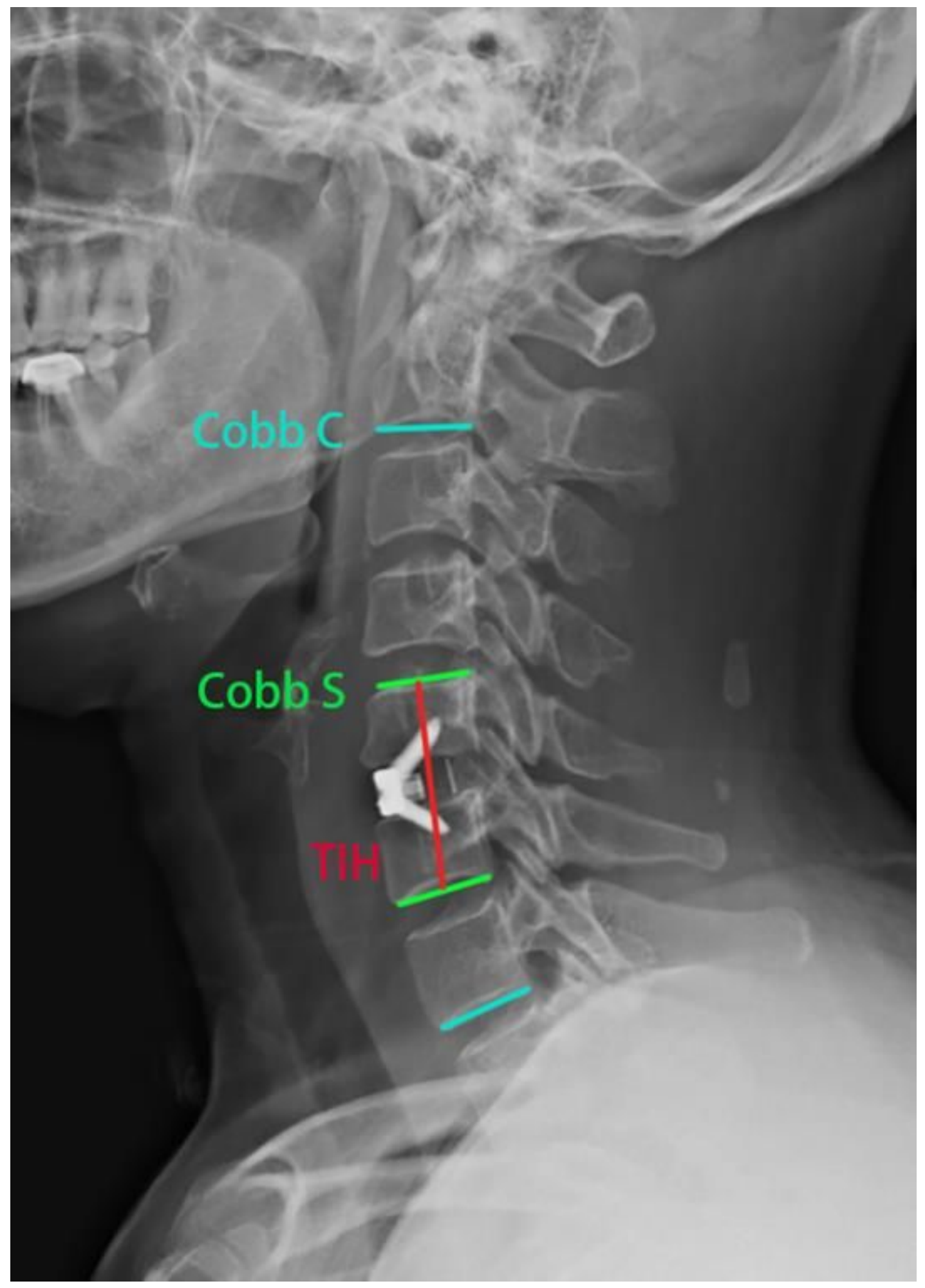

\section{Figure 1}

The lateral X-rays of the cervical vertebra. Cobb C: the Cobb angle between the lines perpendicular to the upper planes of the $\mathrm{C} 2$ vertebral body and the lower plane of the $\mathrm{C} 7$ vertebral body. Cobb $\mathrm{S}$ : the angle between the lines perpendicular to the superior margin of the cranialis vertebral body and the inferior margin of the caudal vertebral body involved in the operation level. $\mathrm{TIH}$ : total interbody height. 


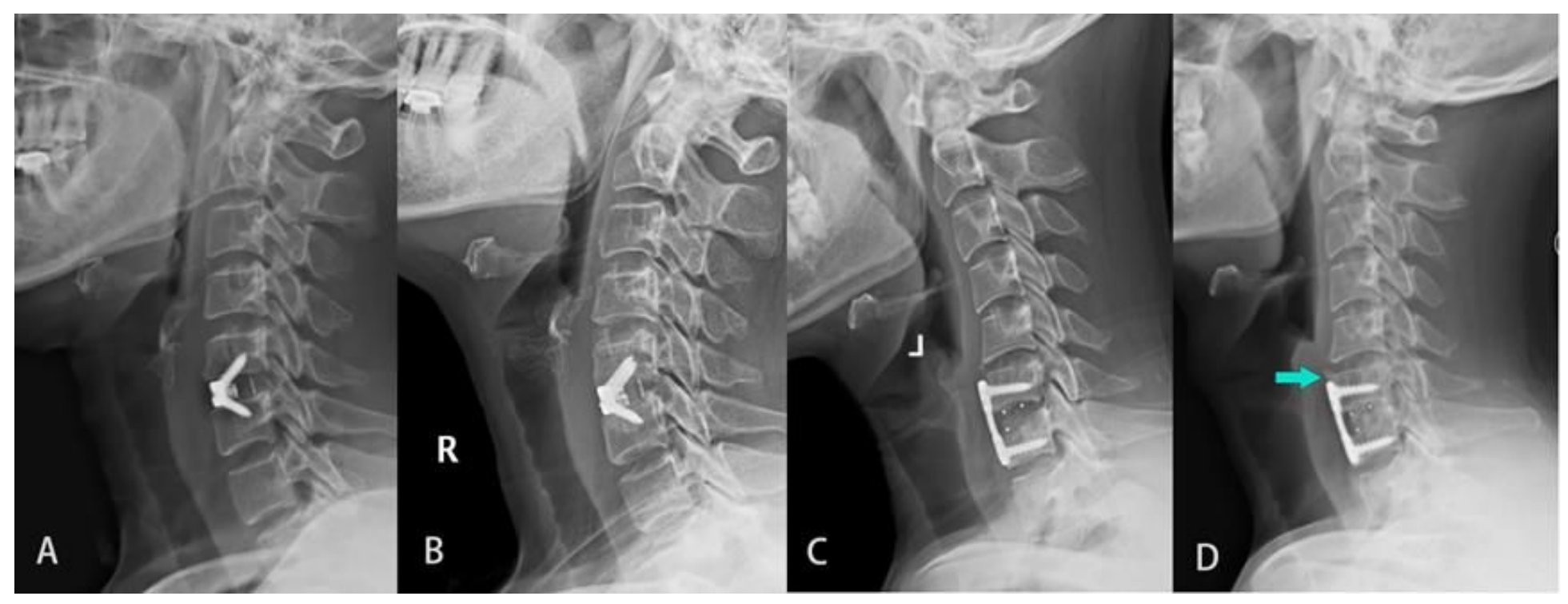

\section{Figure 2}

Lateral X-Rays image of the cervical spine, obtained at 3months postoperative $(A, C)$ and final follow-up $(B, D)$, showing a new anterior bony spurs had formed from the tip of the plate to the upper adjacent level at the final follow-up in Cage group(D). We totally found 4 patients suffered bony spurs in cage group and none in the Zero-p group. 